\title{
Mesothelioma with rhabdoid features: an ultrastructural and immunohistochemical study of 10 cases
}

\author{
Nelson G Ordóñez \\ Department of Pathology, The University of Texas MD Anderson Cancer Center, Houston, TX, USA
}

\begin{abstract}
Mesotheliomas with rhabdoid morphology are rare and only two individual case reports have been documented in the literature. This author reports a series of 10 cases of mesotheliomas with rhabdoid features, nine of which originated in the pleura and one in the peritoneum. Eight of the patients were men and two were women. Six patients had a history of asbestos exposure. Histologically, seven of the mesotheliomas were epithelioid, two sarcomatoid, and one biphasic. The proportion of the rhabdoid cells seen in these cases constituted 15-75\% of the individual tumors. Cytoplasmic staining in the rhabdoid cells was seen for pan-keratin and vimentin in all 10 cases, for keratin 7 in eight of eight, for calretinin in nine of 10, and for keratin 5/6 in seven of nine. Nuclear positivity for WT1 was observed in the rhabdoid cells of four of seven cases and membranous reactivity for mesothelin in four of six, and for podoplanin in two of six. Only one case showed desmin positivity in sparse cells in the nonrhabdoid component of the tumor. All of the cases were negative for CEA, MOC-31, TAG-72, CD15, CD34, bcl2, muscle-specific actin, and TTF-1. Ultrastructural studies revealed paranuclear collections of intermediate filaments, but no evidence of rhabdomyoblastic differentiation was seen. The mean survival of five of the six patients for whom this information was available was 3.8 months. The remaining patient had a survival time of 1 year. It is important for pathologists to be aware that mesotheliomas can present rhabdoid features, not only because they can be confused with other malignancies that can exhibit a similar morphology, but also because of their apparently unusually aggressive behavior. The value of immunohistochemistry and electron microscopy in the differential diagnosis of these tumors is discussed.
\end{abstract}

Modern Pathology (2006) 19, 373-383. doi:10.1038/modpathol.3800543; published online 6 January 2006

Keywords: mesothelioma; rhabdoid; immunohistochemistry; electron microscopy

In 1978, Beckwith and Palmer ${ }^{1}$ identified a group of renal tumors occurring in infants and young children that were characterized by a proliferation of noncohesive or loosely cohesive cells having abundant cytoplasm, a large eccentric nucleus with a prominent nucleolus, and a hyaline intracytoplasmic inclusion displacing the nucleus. Since subsequent ultrastructural $^{2,3}$ and immunohistochemical ${ }^{4}$ investigations of these cells did not show any evidence of rhabdomyoblastic differentiation, the descriptive term rhabdoid was introduced to designate these neoplasms, ${ }^{2}$ thus emphasizing their resemblance to rhabdomyosarcomas. Following these publications, numerous reports of tumors having rhabdoid cells and occurring in a wide variety of extrarenal locations appeared in the

Correspondence: Dr NG Ordóñez, MD, Department of Pathology, The University of Texas MD Anderson Cancer Center, 1515 Holcombe Blvd., Houston, TX 77030, USA.

E-mail: nordonez@mdanderson.org

Received 6 October 2005; accepted 16 November 2005; published online 6 January 2006 literature which resulted in considerable debate regarding the nomenclature and histogenesis of these tumors. Current information indicates that rhabdoid tumors exist both as a specific entity and as a secondary morphologic phenotype that is encountered within a wide array of tumor types originating in a variety of locations, typically indicating the development of cytologic anaplasia and aggressive biological behavior. The tumors in the latter group characteristically show a mixture of a recognizable parent neoplasm admixed with a rhabdoid component and are usually referred to as composite rhabdoid tumors. ${ }^{5}$

A well-known characteristic of mesotheliomas is their ability to exhibit a broad range of cytomorphologic features and to grow in a wide variety of histologic patterns. Based on their light microscopic appearance, these tumors have been subdivided into epithelioid, sarcomatoid, mixed epithelioid and sarcomatoid (biphasic), and desmoplastic types. Although epithelioid mesotheliomas more often present a tubulopapillary or solid pattern, on occasion, they may present other patterns, including 
deciduoid, clear cell, signet ring, and pleomorphic. Mesotheliomas presenting rhabdoid features are rare and, to my knowledge, only two individual case reports of such tumors have been published. ${ }^{6,7}$ Since mesotheliomas with rhabdoid features can potentially be confused with a variety of other tumors with similar morphologic features, especially in small biopsies, the purpose of this study is to make pathologists aware of the existence of this uncommon morphologic variant of mesothelioma and also to discuss the value of electron microscopy and immunohistochemistry in its diagnosis.

\section{Materials and methods}

A total of 10 mesothelioma cases were obtained from the files of the Department of Pathology, and the Electron Microscopy section at the University of Texas MD Anderson Cancer Center, and from the personal consultation files of the author. The specimens consisted of three pleural biopsies, one decortication specimen, six extrapleural pneumonectomy specimens, and biopsies from the omentum and periumbilical mass in one case, and autopsy material in one case.
Tissue specimens were fixed in $10 \%$ buffered formalin and processed for routine light microscopy. Tissue sections from the paraffin blocks were stained with hematoxylin and eosin. Immunohistochemical studies were carried out on formalin-fixed, paraffin-embedded tissue sections using the avidinbiotin-peroxidase complex method in a Dako AutoStainer (Carpinteria, CA, USA). The primary antibodies that were used are listed in Table 1. The immunostaining was carried out using the LSAB2 peroxidase kit (Dako). To enhance the immunostaining, a heat epitope retrieval procedure was performed using a Black-and-Decker (Shelton, CT, USA) vegetable steamer. Briefly, deparaffinized sections were placed in a thermoresistant container filled with a buffer solution, steamed for $45 \mathrm{~min}$, then cooled for $20 \mathrm{~min}$ before immunostaining. Depending on the antibody, the buffer solutions used were either sodium citrate buffer, $\mathrm{pH}$ 6.0, or a 10:1 solution of Tris-EDTA buffer, pH 8.0. Enzymatic pretreatment with $0.2 \%$ protease, type XXIV, (Sigma Chemical, St Louis, MO, USA) in Tris-EDTA buffer saline, $\mathrm{pH} 7.3$, at room temperature for $2 \mathrm{~min}$, was used with the Ber-EP4 antibody. The antigen-antibody reaction was visualized using 3-amino-9-

Table 1 Antibodies used in this study

\begin{tabular}{|c|c|c|c|c|}
\hline Marker & Source & Туре & Dilution & Antigen retrieval \\
\hline Calretinin & $\begin{array}{l}\text { Zymed } \\
\text { (South San Francisco, CA, USA) }\end{array}$ & PAb (rabbit) & $1: 20$ & Yes (citrate) \\
\hline CD15 & $\begin{array}{l}\text { Becton-Dickinson } \\
\text { (Mountainview, CA, USA) }\end{array}$ & Leu-M1 MAb & $1: 40$ & Yes (Tris-EDTA) \\
\hline CEA & $\begin{array}{l}\text { NeoMarkers } \\
\text { (Fremont, CA, USA) }\end{array}$ & PAb (rabbit) & $1: 175$ & No \\
\hline Desmin & $\begin{array}{l}\text { Dako Corporation } \\
\text { (Carpinteria, CA, USA) }\end{array}$ & D33 MAb & & Yes (citrate) \\
\hline $\begin{array}{l}\text { Keratin } 5 / 6 \\
\text { Keratin } 7\end{array}$ & $\begin{array}{l}\text { Dako Corporation } \\
\text { Dako Corporation }\end{array}$ & $\begin{array}{l}\text { D5/16B4 MAb } \\
\text { OV-TL 12/30 MAb }\end{array}$ & $1: 100$ & $\begin{array}{l}\text { Yes (citrate) } \\
\text { Yes (enzymatic digestion) }\end{array}$ \\
\hline $\begin{array}{l}\text { MSA } \\
\text { Mesothelin }\end{array}$ & $\begin{array}{l}\text { Dako Corporation } \\
\text { Novocastra } \\
\text { (Newcastle-upon-Tyne, UK) }\end{array}$ & $\begin{array}{l}\text { HHF35 } \\
\text { 5B2 MAb }\end{array}$ & $\begin{array}{l}1: 75 \\
1: 30\end{array}$ & $\begin{array}{l}\text { Yes (citrate) } \\
\text { Yes (Tris-EDTA) }\end{array}$ \\
\hline $\begin{array}{l}\text { MOC-31 } \\
\text { Pan-keratin }\end{array}$ & $\begin{array}{l}\text { Dako Corporation } \\
\text { Dako Corporation } \\
\text { Becton-Dickinson }\end{array}$ & $\begin{array}{l}\text { MAb } \\
\text { AE1/AE3+ } \\
\text { CAM } 5.2\end{array}$ & $\begin{array}{l}1: 50 \\
1: 500 \\
1: 50\end{array}$ & $\begin{array}{l}\text { Yes (citrate) } \\
\text { Yes (enzymatic digestion) }\end{array}$ \\
\hline Podoplanin & $\begin{array}{l}\text { Signet Laboratories } \\
\text { (Dedham, MA, USA) }\end{array}$ & $\mathrm{D} 2-40 \mathrm{MAb}$ & $1: 50$ & Yes (Tris-EDTA) \\
\hline TAG-72 & $\begin{array}{l}\text { BioGenex } \\
\text { (San Ramon, CA, USA) }\end{array}$ & B72.3 MAb & $1: 300$ & No \\
\hline $\begin{array}{l}\text { TTF-1 } \\
\text { CD34 } \\
\text { bcl-2 } \\
\text { Vimentin } \\
\text { WT1 }\end{array}$ & $\begin{array}{l}\text { Dako Corporation } \\
\text { Becton-Dickinson } \\
\text { BioGenex } \\
\text { Dako Corporation } \\
\text { Dako Corporation }\end{array}$ & $\begin{array}{l}\text { 8G7G3/1 MAb } \\
\text { My10 MAb } \\
\text { MAb } \\
\text { V9 MAb } \\
\text { 6F-H2 MAb }\end{array}$ & $\begin{array}{l}1: 25 \\
1: 20 \\
1: 200 \\
1: 600 \\
1: 40\end{array}$ & $\begin{array}{l}\text { Yes (citrate) } \\
\text { Yes (citrate) } \\
\text { Yes (Tris-EDTA) } \\
\text { Yes (citrate) } \\
\text { Yes (Tris-EDTA) }\end{array}$ \\
\hline
\end{tabular}

$\mathrm{CEA}=$ carcinoembryonic antigen; TTF-1 = thyroid transcription factor-1; MSA = muscle-specific actin. 
ethylcarbazole or 3,3'-diaminobenzidine tetrahydrochloride as chromogen. To evaluate the specificity of the antibodies, known positive and negative tissues were used as controls. The immunostaining was graded on a sliding scale of $1+$ to $4+$ according to the percentage of reactive cells (trace, $<1 \% ; 1+$, $1-25 \%$; $2+, 26-50 \% ; 3+, 51-75 \% ; 4+, 76-100 \%$ ). Electron microscopy studies were performed in nine of the cases. Samples of the specimens were fixed in $2 \%$ buffered glutaraldehyde and embedded in Epon epoxy resin. Ultrathin sections were stained with uranyl acetate and lead citrate.

\section{Results}

\section{Clinical Findings}

Eight patients were men and two were women ranging in age from 52 to 79 years (mean, 62.8 years). There was a history of asbestos exposure in six patients and smoking in three. The mesothelioma originated in the pleura in nine cases and in the peritoneum in one. Two patients received chemotherapy alone; five underwent extrapleural pneumonectomy with four of these also receiving radiation therapy and one chemotherapy. One patient underwent decortication. Treatment information was not available in the remaining two patients. All six patients for whom follow-up information was available died of disease 3-12 months after diagnosis (mean, 5.7 months).

\section{Pathology Findings}

Gross examination of the five pneumonectomy specimens showed diffuse involvement of the visceral and parietal pleura with encasement of the lung. In two of the cases (cases 7 and 8), several of the peribronchial lymph nodes were involved by metastases. The most significant light microscopic findings are summarized in Table 2. Histologically, seven of the mesotheliomas were epithelioid, two sarcomatoid, and one biphasic. The proportion of the rhabdoid component in these tumors ranged from 15 to $75 \%$, and all were characterized by the presence of discohesive cells having abundant eosinophilic cytoplasm, an eccentric nucleus with a prominent nucleolus, and a rounded, eosinophilic cytoplasmic inclusion that sometimes caused nuclear indentation (Figure 1).

\section{Immunohistochemistry}

The immunohistochemical results are summarized in Table 3. The rhabdoid cells in all 10 cases strongly reacted for vimentin and pan-keratin, and a globoid-like inclusion was often apparent in the neoplastic cells (Figures 2a and b). Expression for keratin 7 was seen in all eight of the cases stained for this marker and in most instances, the reactivity was strong and diffuse (Figure 2c). The rhabdoid cells also stained for calretinin in nine of 10 cases and for keratin 5/6 in seven of nine (Figure 2d). These cells also exhibited nuclear positivity for WT1 in four of seven cases, and membranous reactivity for mesothelin in four of six and podoplanin in two of six (Figures 2e and f). Only one case showed focal positivity for desmin, but the staining occurred in the nonrhabdoid cells. None of the cases stained for muscle-specific actin, bcl-2, CD15, CD34, TAG-72 (B72.3), CEA, MOC-31, or TTF-1 were positive for any of these markers in either the rhabdoid cells or in the nonrhabdoid component of the tumors.

\section{Electron Microscopy}

Electron microscopy demonstrated that the rhabdoid cells had a peripherally placed nucleus often containing a prominent nucleolus (Figures 3a, b, and 4). The cytoplasm was abundant and contained paranuclear collections of intermediate filaments

Table 2 Summary of clinical and pathology findings

\begin{tabular}{|c|c|c|c|c|c|c|}
\hline Case & Sex/age & Type of specimen & Location & $\begin{array}{l}\text { Histologic type } \\
\text { (\% rhabdoid cells) }\end{array}$ & Treatment & Follow-up (months) \\
\hline 1 & $\mathrm{M} / 72$ & Pleural biopsy & Rt. pleura & Epithelioid (40) & Chemotherapy & DOD (3) \\
\hline 2 & $\mathrm{M} / 65$ & Decortication & Rt. pleura & Epithelioid (40) & Decortication & DOD (3) \\
\hline 3 & $\mathrm{M} / 53$ & Pneumonectomy & Rt. pleura & Epithelioid (70) & Pneumonectomy+radiation & DOD (12) \\
\hline 4 & $\mathrm{~F} / 79$ & Pleural biopsy & Rt. pleura & Epithelioid (15) & INA & INA \\
\hline 5 & $\mathrm{M} / 52$ & Pneumonectomy & Rt. pleura & Biphasic (40) & $\begin{array}{l}\text { Pneumonectomy+radiation+ } \\
\text { chemotherapy }\end{array}$ & DOD (6) \\
\hline 6 & $\mathrm{~F} / 66$ & $\begin{array}{l}\text { Periumbilical mass } \\
\text { and omental biopsies }\end{array}$ & Abdomen & Epithelioid (70) & INA & DOD (3) \\
\hline 7 & $\mathrm{M} / 57$ & Pneumonectomy & Rt. pleura & Epithelioid (50) & Pneumonectomy+radiation & INA \\
\hline 8 & $\mathrm{M} / 59$ & Pneumonectomy & Rt. pleura & Epithelioid (75) & Pneumonectomy+radiation & INA \\
\hline 9 & $\mathrm{M} / 61$ & Pneumonectomy & Rt. pleura & Sarcomatoid (70) & Pneumonectomy+chemotherapy & INA \\
\hline 10 & $\mathrm{M} / 74$ & $\begin{array}{l}\text { Pleural biopsy, } \\
\text { autopsy abdomen }\end{array}$ & Rt. pleura & Sarcomatoid (50) & Chemotherapy & DOD (4) \\
\hline
\end{tabular}

$\mathrm{DOD}=$ died of disease; INA $=$ information not available 

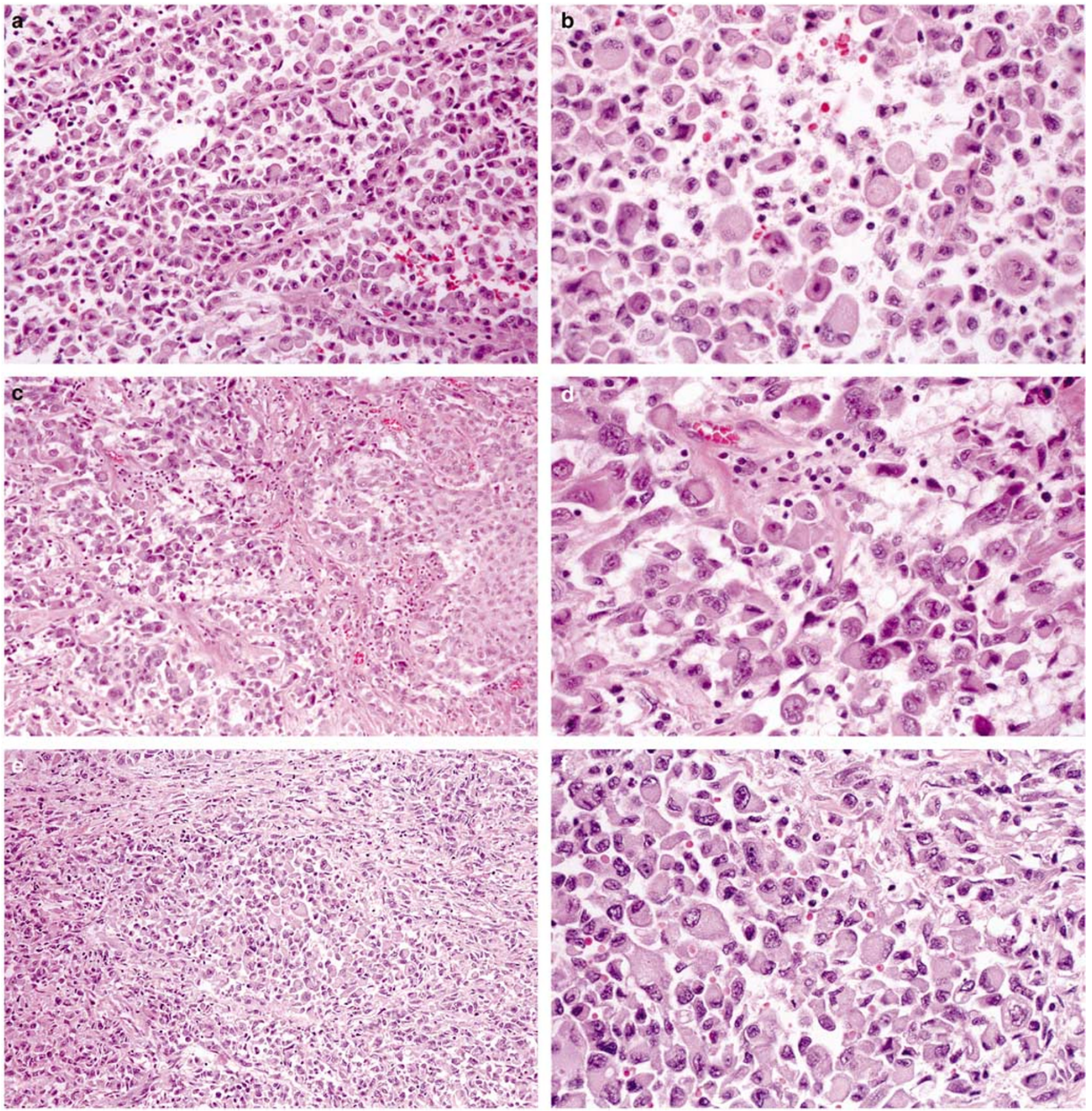

Figure 1 Case 8: (a) Rhabdoid cells arranged in an alveolar pattern. (b) Higher magnification showing discohesive cells with rhabdoid features. Case 7: (c) In this mesothelioma, the rhabdoid cells are primarily located in the areas of the tumor with myxoid stroma. (d) Higher magnification showing rhabdoid cells with typical cytoplasmic inclusions. (e) Case 10: Sarcomatoid mesothelioma showing an area of discohesive cells exhibiting rhabdoid morphology. (f) Higher magnification of the rhabdoid cells.

which occupied most of the cytoplasm. These intermediate filaments were arranged in either interlacing bundles or a whorl-like array (Figures $3 \mathrm{~b}$ and 4). In some instances, a variable number of organelles appeared entrapped within the intermediate filaments (Figure 3b). The cell membrane of the cells showing early rhabdoid changes were covered by a variable number of short microvilli which were usually seen along the apical and lateral surfaces of the cells (Figures 3a and b).

\section{Discussion}

Although malignant rhabdoid tumors were first described in the kidney and were initially consid- 
Table 3 Immunohistochemical results

\begin{tabular}{|c|c|c|c|c|c|c|c|c|c|c|c|c|c|c|c|c|c|c|c|c|}
\hline & \multicolumn{2}{|c|}{ Case 1} & \multicolumn{2}{|c|}{ Case 2} & \multicolumn{2}{|c|}{ Case 3} & \multicolumn{2}{|c|}{ Case 4} & \multicolumn{2}{|c|}{ Case 5} & \multicolumn{2}{|c|}{ Case 6} & \multicolumn{2}{|c|}{ Case 7} & \multicolumn{2}{|c|}{ Case 8} & \multicolumn{2}{|c|}{ Case 9} & \multicolumn{2}{|c|}{ Case 10} \\
\hline & $R$ & $N R$ & $R$ & $N R$ & $R$ & $N R$ & $R$ & $N R$ & $R$ & $N R$ & $R$ & $N R$ & $R$ & $N R$ & $R$ & $N R$ & $R$ & $N R$ & $R$ & $N R$ \\
\hline Calretinin & $3+$ & $3+$ & $3+$ & $4+$ & $4+$ & $4+$ & $4+$ & $4+$ & $2+$ & $4+$ & $4+$ & $4+$ & $3+$ & $3+$ & $4+$ & $4+$ & 0 & $1+$ & $1+$ & $1+$ \\
\hline Pan-Ker & $4+$ & $4+$ & $4+$ & $4+$ & $4+$ & $4+$ & $4+$ & $4+$ & $4+$ & $4+$ & $4+$ & $4+$ & $4+$ & $4+$ & $4+$ & $4+$ & $4+$ & $4+$ & $4+$ & $4+$ \\
\hline Ker 5/6 & ND & ND & $2+$ & $3+$ & $3+$ & $3+$ & $4+$ & $4+$ & 0 & $4+$ & $3+$ & $3+$ & $1+$ & $2+$ & $4+$ & $4+$ & 0 & 0 & $1+$ & $1+$ \\
\hline Ker 7 & ND & ND & $4+$ & $4+$ & $2+$ & $3+$ & ND & ND & $3+$ & $4+$ & $4+$ & $4+$ & $3+$ & $3+$ & $4+$ & $4+$ & $4+$ & $4+$ & $4+$ & $3+$ \\
\hline Vimentin & $3+$ & $3+$ & $3+$ & $3+$ & $3+$ & $3+$ & $3+$ & $3+$ & $3+$ & $3+$ & $3+$ & $3+$ & $4+$ & $3+$ & $3+$ & $3+$ & $4+$ & $4+$ & $4+$ & $4+$ \\
\hline Desmin & ND & ND & 0 & 0 & 0 & 0 & ND & ND & 0 & $1+$ & 0 & 0 & 0 & 0 & 0 & 0 & 0 & 0 & 0 & 0 \\
\hline Mesothelin & ND & ND & ND & ND & $4+$ & $4+$ & ND & ND & 0 & $2+$ & $4+$ & $4+$ & ND & ND & $4+$ & $4+$ & 0 & 0 & \pm & \pm \\
\hline Podoplanin & ND & ND & ND & ND & $3+$ & $3+$ & ND & ND & 0 & 0 & 0 & $2+$ & ND & ND & $2+$ & $2+$ & 0 & 0 & 0 & 0 \\
\hline WT1 & ND & ND & ND & ND & $4+$ & $4+$ & $4+$ & $4+$ & $2+$ & $2+$ & $3+$ & $3+$ & ND & ND & 0 & 0 & 0 & 0 & 0 & 0 \\
\hline MOC-31 & 0 & 0 & 0 & 0 & 0 & 0 & 0 & 0 & 0 & 0 & 0 & 0 & 0 & 0 & 0 & 0 & 0 & 0 & 0 & 0 \\
\hline CEA & 0 & 0 & 0 & 0 & 0 & 0 & 0 & 0 & 0 & 0 & 0 & 0 & 0 & 0 & 0 & 0 & 0 & 0 & 0 & 0 \\
\hline TAG-72 & 0 & 0 & 0 & 0 & 0 & 0 & ND & ND & 0 & 0 & 0 & 0 & 0 & 0 & 0 & 0 & 0 & 0 & 0 & 0 \\
\hline TTF-1 & ND & ND & 0 & 0 & 0 & 0 & ND & ND & 0 & 0 & ND & ND & 0 & 0 & 0 & 0 & 0 & 0 & 0 & 0 \\
\hline CD15 & ND & ND & 0 & 0 & 0 & 0 & ND & ND & 0 & 0 & 0 & 0 & 0 & 0 & 0 & 0 & 0 & 0 & 0 & 0 \\
\hline CD34 & ND & ND & ND & ND & 0 & 0 & ND & ND & 0 & 0 & ND & ND & ND & ND & 0 & 0 & 0 & 0 & 0 & 0 \\
\hline bcl-2 & ND & ND & ND & ND & 0 & 0 & ND & ND & 0 & 0 & ND & ND & 0 & 0 & 0 & 0 & 0 & 0 & 0 & 0 \\
\hline MSA & ND & ND & ND & ND & 0 & 0 & ND & ND & 0 & 0 & 0 & 0 & 0 & 0 & 0 & 0 & 0 & 0 & 0 & 0 \\
\hline
\end{tabular}

$\mathrm{R}=$ rhabdoid; $\mathrm{NR}=$ nonrhabdoid; Ker = keratin; CEA = carcinoembryonic antigen; TTF-1 = thyroid transcription factor-1; MSA = muscle-specific antigen; $\mathrm{ND}=$ not done.

ered to represent an especially aggressive Wilms' tumor with a rhabdomyosarcomatous pattern, examples of tumors exhibiting rhabdoid features were subsequently reported in a wide variety of other anatomic sites including the central nervous system, ${ }^{8,9}$ skin, ${ }^{10,11}$ liver, ${ }^{12,13}$ gastrointestinal tract, ${ }^{14}$ lung, ${ }^{15-18}$ bladder, ${ }^{19,20}$ thymus, ${ }^{21}$ tongue, ${ }^{22}$ vulva, ${ }^{23}$ and soft tissue, ${ }^{24-26}$ and as a variant of melanoma. ${ }^{27-29}$ At present, only malignant rhabdoid tumors of the kidney and atypical teratoid/rhabdoid tumors of the central nervous system are well-defined entities. ${ }^{30-32}$ These tumors are characterized by having a predilection for infants and young children, aggressive clinical behavior with short survival time, a polyphenotypic immunoprofile, and characteristic deletions and mutations involving the INI1/ hSNF5 tumor suppressor gene on chromosome $22 q 11.2 .^{33,34}$ It has been suggested, however, that some other subgroups may exist, especially among those malignant rhabdoid tumors originating in the liver and soft tissue, because they share specific gene alterations and may, therefore, represent specific entities. ${ }^{35,36}$ It should be emphasized, though, that current evidence indicates that the large majority of extrarenal malignant rhabdoid tumors, excluding those previously mentioned, represent a distinct phenotype that is shared by a number of tumors as they undergo anaplastic progression.

Mesotheliomas exhibiting rhabdoid features are rare and only two such cases have been documented in the literature. ${ }^{6,7}$ The first case, which was reported by Matsukuma et al in $1996,{ }^{6}$ was a localized peritoneal malignant mesothelioma in a 68-year-old man with no history of asbestos exposure. Histologically, the tumor was a biphasic mesothelioma containing sarcomatoid cells with rhabdoid features. Immunohistochemical studies demonstrated vimentin, keratin, and epithelial membrane antigen expression in the rhabdoid cells. No reactivity for desmin, myoglobin, actin, or S-100 protein was observed. Electron microscopy studies showed globular aggregates of intermediate filaments but there was no evidence of rhabdomyoblastic differentiation. The second case was a pleural mesothelioma that was reported by Puttagunta et al in $2000 .^{7}$ The patient was a 41 -year-old man with no occupational history of asbestos exposure who had received radiotherapy for mediastinal Hodgkin's disease 14 years earlier. The histological appearance of this tumor was that of a deciduoid mesothelioma with focal rhabdoid change. Immunohistochemical studies showed positive staining for keratin, vimentin, and calretinin, and negative staining for CEA, Ber-EP4, and CD15 (leu-M1). Ultrastructural studies demonstrated paranuclear aggregates of intermediate filaments arranged in a concentric pattern.

The results of the present investigation demonstrated that, in general, the rhabdoid cells tended to maintain the immunophenotype seen in the nonrhabdoid areas of the tumor. In all of the cases, these cells retained the strong expression for vimentin, pan-keratin, keratin 7 , and calretinin that was also seen in the areas of the tumors exhibiting a more conventional morphology. Other mesothelioma markers, specifically keratin 5/6, WT1, mesothelin, and podoplanin, were also demonstrated, but their expression was less frequent and when it occurred, the percentage of cells in the rhabdoid areas expressing these markers was lower when compared with the nonrhabdoid areas of the tumor. These 

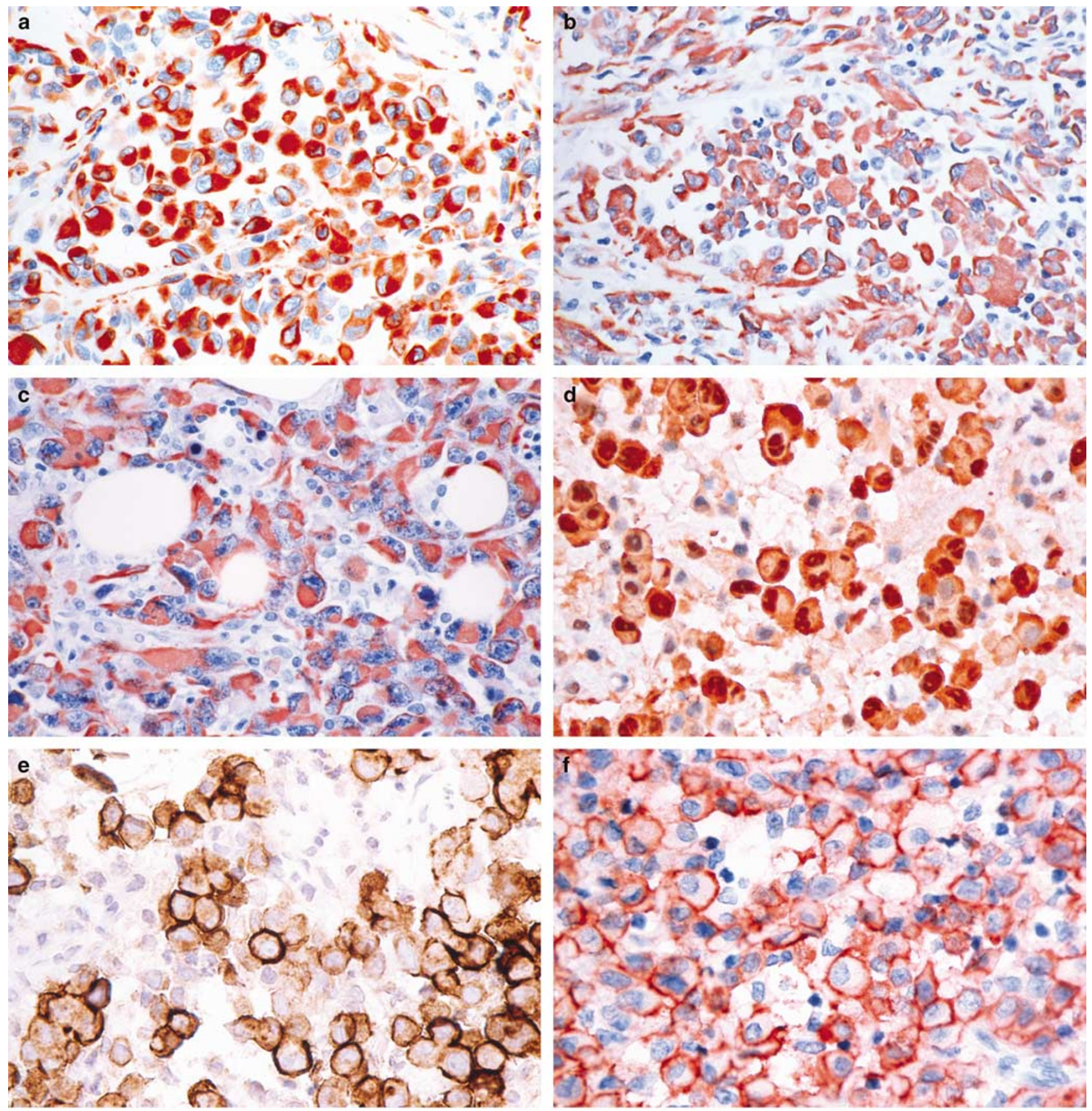

Figure 2 (a) Case 10 showing strong reactivity for vimentin in the rhabdoid cells. (b) The same case as shown in (a) showing positivity for pan-keratin in both the rhabdoid and spindle cells. (c) Case 9 exhibiting strong keratin 7 expression in the rhabdoid cells. (d) Case 6 showing nuclear and cytoplasmic positivity for calretinin in the rhabdoid cells. (e) The same case as shown in (d) showing membranous reactivity for mesothelin in some of the rhabdoid cells. (f) Case 3 showing membranous positivity for podoplanin in the rhabdoid cells.

findings correlate with the ultrastructural demonstration of varying degrees of mesothelial differentiation in the rhabdoid cells. While the more differentiated cells had microvilli on the cell membrane and relatively small nodular aggregates of intermediate filaments, the cell membrane of the less differentiated cells was devoid of microvilli and most of the cytoplasm was occupied by a large collection of intermediate filaments arranged in interlacing fascicles or in a concentric array.

One of the immunohistochemical markers that was found to be expressed in mesotheliomas with rhabdoid features and which merits additional comment is the novel mesothelioma marker podoplanin. Although podoplanin and the recently commercially available D2-40 monoclonal antibody 

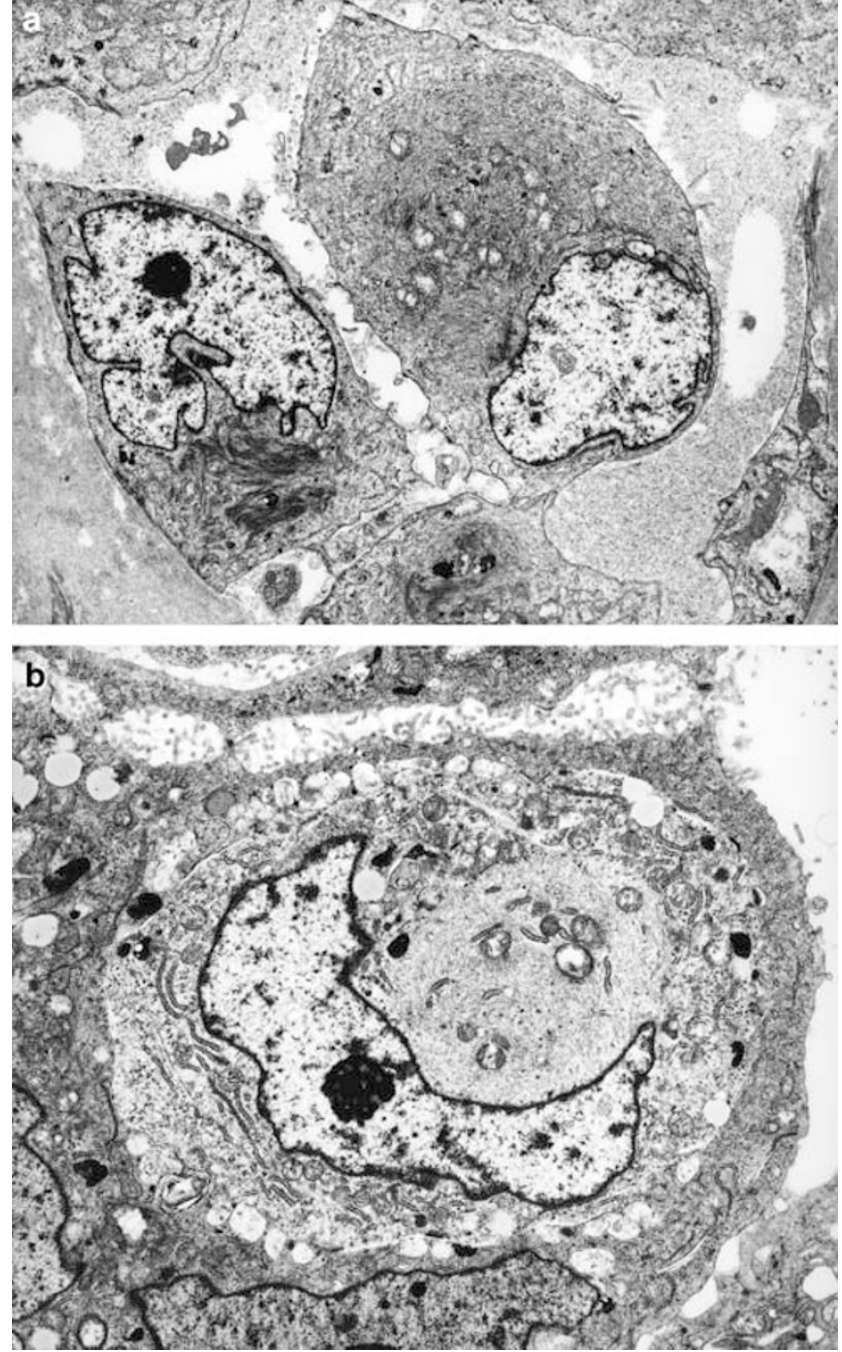

Figure 3 (a) Electron micrograph showing two tumor cells with early rhabdoid features. In both cells, the nuclei are eccentrically placed and the one on the left contains a large nucleolus. A vague globular-like collection of intermediate filaments in the cytoplasm of the cell on the right is also apparent. Only a few short microvilli are seen on the cell membrane of both cells. (b) Tumor cell showing a globoid aggregate of paranuclear cytoplasmic filaments producing compression of the nucleus. A few mitochondria and short profiles of endoplasmic reticulum are seen within the collection of the intermediate filaments. The intercellular space appears dilated and the cell membrane is covered by microvilli. (a) $\times 6700$; (b) $\times 10000$

that was raised against an unidentified M2A protein derived from germ cell tumors were initially considered to be two different mesothelioma markers, recent investigations have shown that D240 specifically recognizes podoplanin,,$^{37}$ a $38 \mathrm{kDa}$ mucin-type transmembrane protein that was first detected on the surface of the rat glomerular epithelial cells (podocytes) and was found to be linked to the flattening of the foot processes in puromycin-induced nephrosis. ${ }^{38}$ As podoplanin was found to be expressed in $86-100 \%$ of the epithelioid mesotheliomas, but absent in lung

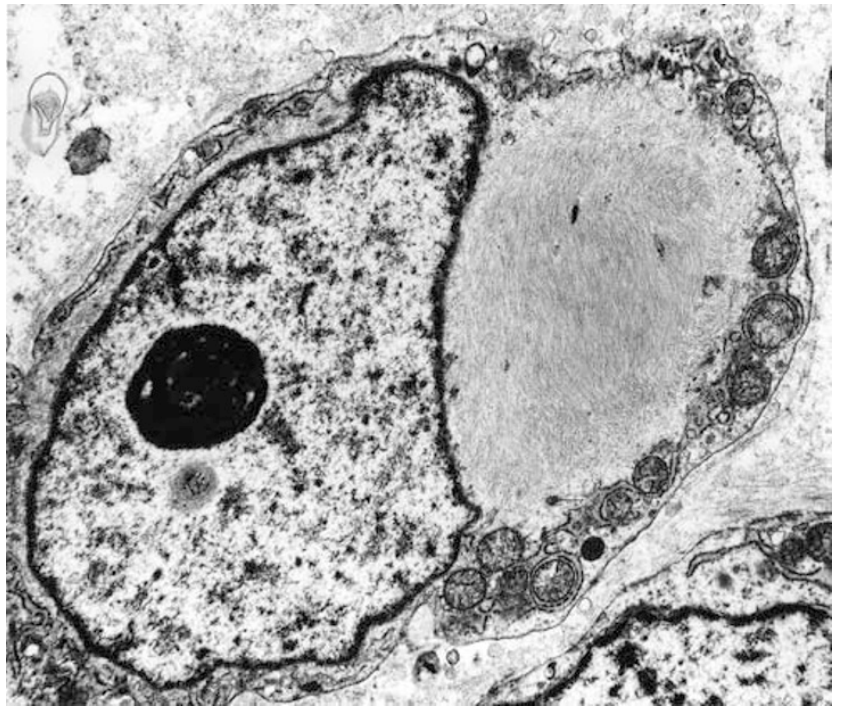

Figure 4 High magnification of a rhabdoid cell showing a large collection of intermediate filaments corresponding to the paranuclear inclusions seen in the rhabdoid cells on light microscopy. The cell membrane appears completely devoid of microvilli $(\times 12000)$.

adenocarcinomas, recent investigations have indicated that immunostaining for this protein could be very useful in distinguishing between these two malignancies. ${ }^{39-42}$ It should be mentioned, however, that in addition to epithelioid mesotheliomas, podoplanin expression has been reported in a subset of angiosarcomas, ${ }^{43,44}$ in a minority of serous carcinomas, ${ }^{39,45}$ in squamous carcinomas of the lung, ${ }^{42,46}$ and in the epithelioid component of biphasic synovial sarcomas. ${ }^{41}$ All of these tumors can potentially be confused with mesotheliomas.

It is important for pathologists to be aware that mesotheliomas can exhibit rhabdoid features and can, therefore, potentially be confused with a variety of tumors with similar morphology that can involve the serosal membranes. The four tumors with the greatest potential of being confused with mesotheliomas with rhabdoid features are lung carcinomas with rhabdoid features, proximal-type epithelioid sarcomas, synovial sarcomas, and rhabdomyosarcomas. Carcinomas of the lung can present rhabdoid features and can involve the pleura. In over half of the published cases of these tumors in which the status of the pleura was mentioned, this structure was reported as being involved by tumor. ${ }^{15-17,47}$ Rare examples of lung carcinomas with rhabdoid features diffusely involving the pleura and clinically and radiologically mimicking mesothelioma have also been documented in the literature. ${ }^{15}$ Immunohistochemical studies can assist in establishing the differential diagnosis. As was demonstrated in this study, mesotheliomas with rhabdoid features often express mesothelial markers (ie, calretinin, WT1, podoplanin, mesothelin) that are usually absent in carcinomas. $^{41,48}$ It should be mentioned, however, 
that TTF-1, a marker that is frequently expressed in lung carcinomas, ${ }^{48,49}$ is usually absent in carcinomas of the lung with rhabdoid features. ${ }^{18}$ In a recent investigation, no reactivity for TTF-1 was seen in the rhabdoid areas of 11 carcinomas of the lung with rhabdoid features and only three of these 11 cases focally expressed this marker in the nonrhabdoid component of the tumor. ${ }^{18}$ Additionally, while keratin 7 , which is usually present in both mesotheliomas and adenocarcinomas of the lung, was found to be strongly expressed in the rhabdoid component of the mesotheliomas, it was rarely demonstrated in the rhabdoid component of the lung carcinomas.

Mesotheliomas with rhabdoid features can also be confused with proximal-type epithelioid sarcoma, a tumor that is primarily composed of rhabdoid cells and which, like mesotheliomas, can originate in the inguinal region. ${ }^{50,51}$ Similar to mesotheliomas, the rhabdoid cells in epithelioid sarcomas express vimentin and keratin and on occasion, some mesothelioma markers such as keratin 5/6 and calretinin..$^{52}$ However, in contrast to mesotheliomas, epithelioid sarcomas frequently express CD34, ${ }^{52-54}$ a marker that has been reported to be invariably absent in mesotheliomas. ${ }^{55,56}$

Synovial sarcomas can originate in or metastasize to the pleura or the chest wall and, like mesotheliomas, may present a wide variety of morphologic appearances, including a rhabdoid morphology. ${ }^{57,58}$ Additionally, these tumors may also express some mesothelioma markers, including calretinin, mesothelin, and podoplanin. ${ }^{41,59}$ However, synovial sarcomas do not exhibit positivity for WT1, a marker that is often expressed in mesotheliomas; therefore, immunostaining for the WT1 protein may assist in establishing the differential diagnosis between these malignancies. ${ }^{59}$ Another immunohistochemical marker that can also be useful in this differential diagnosis is bcl-2 which has been reported to be expressed in $79-100 \%$ of the synovial sarcomas, but in only $0-10 \%$ of the mesotheliomas. ${ }^{60-63}$ The diagnosis of synovial sarcoma can also be established by the demonstration of the distinctive $t(x ; 18)(p 11 ; q 11)$ translocation that has been reported to be present in nearly all of the cases. ${ }^{64,65}$

Finally, mesotheliomas with rhabdoid features can be distinguished from rhabdomyosarcomas by the expression of mesothelial markers in the mesotheliomas or by the demonstration of rhabdomyoblastic markers, such as myogenin or MyoD1, in rhabdomyosarcomas. These rhabdomyoblastic regulatory proteins are often expressed in rhabdomyosarcomas, ${ }^{66,67}$ but are absent in mesotheliomas. ${ }^{68}$ Desmin is another marker that is frequently used in the diagnosis of rhabdomyosarcomas and, although it has been reported to be present in mesotheliomas, controversy exists regarding the percentage of desmin positivity in the latter tumors. While some groups of investigators have reported expression of this protein in $41-88 \%$ of the epithelioid ${ }^{69-71}$ and in $33-71 \%$ of the sarcomatoid ${ }^{69,70,72}$ mesotheliomas, others have reported desmin positivity in $0-10 \%$ of the epithelioid ${ }^{68,73-76}$ and in none of the sarcomatoid. ${ }^{74-76}$ Of the eight cases investigated for desmin expression in the present study, only one exhibited positivity in sparse groups of neoplastic cells in the nonrhabdoid component of the tumor, a finding which confirms previous observations indicating that desmin can be expressed in mesotheliomas but it is a relatively uncommon phenomenon. Electron microscopy can also be useful since rhabdomyosarcomas would exhibit rhabdomyoblastic differentiation.

The results of the present investigation suggest that the presence of rhabdoid features in a mesothelioma is an indication of particularly aggressive behavior as shown by the short survival time of the six patients for whom follow-up information was available. With the exception of one patient who survived for 1 year after diagnosis, all of the remaining patients died within a 6-month period (mean survival, 3.8 months). A further indication of the aggressive behavior of these tumors was the extensive lymph node involvement that was found in the pathology specimens of two of the five patients who underwent extrapleural pneumonectomy. Perhaps this aggressive behavior should not be surprising, however, given that other tumors originating in a variety of locations and exhibiting the rhabdoid phenotype have often been reported as being unusually aggressive when compared with their more histologically conventional counterparts. In order to fully determine the prognostic significance of the rhabdoid phenotype in mesotheliomas, more studies with larger numbers of cases are needed.

\section{Acknowledgements}

I thank Janet Quiñones, Raju Nandagiri, Maria Grimberg-Siehien, Kim-Anh $\mathrm{Vu}$, and Mannie Steglich for technical assistance and Asuncion Moroi for secretarial assistance.

\section{References}

1 Beckwith JB, Palmer NF. Histopathology and prognosis of Wilms' tumors: results from the first National Wilms' tumor study. Cancer 1978;41:1937-1948.

2 Haas JE, Palmer NF, Weinberg AG, et al. Ultrastructure of malignant rhabdoid tumor of the kidney: a distinctive renal tumor of children. Hum Pathol 1981;12: 646-657.

3 Fung CH, Gonzalez-Crussi F, Yonan TN, et al. Rhabdoid. Wilms' tumor: an ultrastructural study. Arch Pathol Lab Med 1981;105:521-523.

4 Rutledge J, Beckwith JB, Benjamin D, et al. Absence of immunoperoxidase staining for myoglobin in the malignant rhabdoid tumor of the kidney. Pediatr Pathol 1983;1:93-98. 
5 Wick MR, Ritter JH, Dehner LP. Malignant rhabdoid tumors: a clinicopathologic review and conceptual discussion. Semin Diagn Pathol 1995;12:233-248.

6 Matsukuma S, Aida S, Hata Y, et al. Localized malignant peritoneal mesothelioma containing rhabdoid cells. Pathol Int 1996;46:389-391.

7 Puttagunta L, Vriend RA, Nguyen G-K. Deciduoid epithelial mesothelioma of the pleura with focal rhabdoid change (letter). Am J Surg Pathol 2000;24: 1440-1443.

8 Agranovich AL, Ang LC, Griebel RW, et al. Malignant rhabdoid tumor of the central nervous system with subarachnoid dissemination. Surg Neurol 1992;37: 410-414.

9 Biggs PJ, Garen PD, Powers JM, et al. Malignant rhabdoid tumor of the central nervous system. Hum Pathol 1987;18:332-337.

10 Perez-Atayde AR, Newbury R, Fletcher JA, et al. Congenital 'neurovascular hamartoma' of the skin. A possible marker of malignant rhabdoid tumor. Am J Surg Pathol 1994;18:1030-1038.

11 Sangueza OP, Meshul CK, Sangueza P, et al. Rhabdoid tumor of the skin. Int J Dermatol 1992;31:484-487.

12 Foschini MP, Eyken PV, Brock PR, et al. Malignant rhabdoid tumor of the liver. A case report. Histopathology 1992;20:157-165.

13 Hunt SJ, Anderson WD. Malignant rhabdoid tumor of the liver. A distinct clinicopathologic entity. Am J Clin Pathol 1990;94:645-648.

14 Amrikachi M, Ro JY, Ordóñez NG, et al. Adenocarcinomas of the gastrointestinal tract with prominent rhabdoid features. Ann Diagn Pathol 2002;6:357-363.

15 Attems JH, Lintner F. Pseudomesotheliomatous adenocarcinoma of the lung with rhabdoid features. Pathol Res Pract 2001;197:841-846.

16 Cavazza A, Colby TV, Tsokos M, et al. Lung tumors with a rhabdoid phenotype. Am J Clin Pathol 1996; 105:182-188.

17 Miyagi J, Tsuhako K, Kinjo T, et al. Rhabdoid tumour of the lung is a dedifferentiated phenotype of pulmonary adenocarcinoma. Histopathology 2000;37:37-44.

18 Tamboli P, Toprani TH, Amin MB, et al. Carcinoma of lung with rhabdoid features. Hum Pathol 2004;35: 8-13.

19 Egawa S, Uchida T, Koshiba K, et al. Malignant fibrous histiocytoma of the bladder with focal rhabdoid tumor differentiation. J Urol 1994;151:154-156.

20 Harris M, Eyden BP, Joglekar VM. Rhabdoid tumour of the bladder: a histological, ultrastructural and immunohistochemical study. Histopathology 1987;11: 1083-1092.

21 Toprani TH, Tamboli P, Amin MB, et al. Thymic carcinoma with rhabdoid features. Ann Diagn Pathol 2003;7:106-111.

22 Patron M, Palacios J, Rodriguez-Peralto JL, et al. Malignant rhabdoid tumor of the tongue. A case report with immunohistochemical and ultrastructural findings. Oral Surg Oral Med Oral Pathol 1988;65: 67-70.

23 Kudo E, Hirose T, Fujii Y, et al. Undifferentiated carcinoma of the vulva mimicking epithelioid sarcoma. Am J Surg Pathol 1991;15:990-1001.

24 Tsokos M, Kouraklis G, Chandra RS, et al. Malignant rhabdoid tumor of the kidney and soft tissues. Evidence for a diverse morphologic and immunocytochemical phenotype. Arch Pathol Lab Med 1989;113: 115-120.
25 Tsuneyoshi M, Daimaru Y, Hashimoto $\mathrm{H}$, et al. Malignant soft tissue neoplasms with the histologic features of renal rhabdoid tumors: an ultrastructural and immunohistochemical study. Hum Pathol 1985; 16:1235-1242.

26 Tsuneyoshi M, Daimaru Y, Hashimoto H, et al. The existence of rhabdoid cells in specified soft tissue sarcomas. Histopathologic, ultrastructural and immunohistochemical evidence. Virchows Arch A 1987;411: 509-514.

27 Abbott JJ, Amirkhan RH, Hoang MP. Malignant melanoma with a rhabdoid phenotype: histologic, immunohistochemical, and ultrastructural study of a case and review of the literature. Arch Pathol Lab Med 2004;128:686-688.

28 Bittesini L, Dei Tos AP, Fletcher CDM. Metastatic malignant melanoma showing a rhabdoid phenotype: further evidence of a nonspecific histologic pattern. Histopathology 1992;20:167-170.

29 Chang ES, Wick MR, Swanson PE, et al. Metastatic malignant melanoma with 'rhabdoid' features. Am J Clin Pathol 1994;102:426-431.

30 Biegel JA, Rorke LB, Packer RJ, et al. Monosomy 22 in rhabdoid or atypical tumors of the brain. J Neurosurg 1990;73:710-714.

31 Biegel JA, Burk CD, Parmiter AH, et al. Molecular analysis of a partial deletion in a central nervous system rhabdoid tumor. Genes Chromosomes Cancer 1992;5:104-108.

32 Fuller CE, Pfeifer J, Humphrey P, et al. Chromosome $22 q$ dosage in composite extrarenal rhabdoid tumors: clonal evolution or a phenotypic mimic? Hum Pathol 2001;32:1102-1108.

33 Uno K, Takita J, Yokomori K, et al. Aberrations of the hSNF5/INI1 gene are restricted to malignant rhabdoid tumors or atypical teratoid/rhabdoid tumors in pediatric solid tumors. Genes Chromosomes Cancer 2002;34: 33-41.

34 Versteege I, Sevenet N, Lange J, et al. Truncating mutations of hSNF5/INI1 in aggressive paediatric cancer. Nature 1998;394:203-206.

35 Douglass EC, Valentine M, Rowe ST, et al. Malignant rhabdoid tumor: a highly malignant childhood tumor with minimal karyotypic changes. Genes Chromosomes Cancer 1990;2:210-216.

36 White FV, Dehner LP, Belchis DA, et al. Congenital disseminated malignant rhabdoid tumor: a distince clinicopathological entity demonstrating abnormalities of chromosome 22q11. Am J Surg Pathol 1999; 23:249-256.

37 Schacht V, Dadras SS, Johnson LA, et al. Up-regulation of the lymphatic marker podoplanin, a mucin-type transmembrane glycoprotein, in human squamous cell carcinomas and germ cell tumors. Am J Pathol 2005; 166:913-921.

38 Breiteneder-Geleff S, Matsui K, Soleiman A, et al. Podoplanin, novel 43-kd membrane protein of glomerular epithelial cells, is down-regulated in puromycin nephrosis. Am J Pathol 1997;151:1141-1152.

39 Chu AY, Litzky LA, Pasha TL, et al. Utility of D2-40, a novel mesothelial marker, in the diagnosis of malignant mesothelioma. Mod Pathol 2005;18: 105-110.

40 Kimura N, Kimura I. Podoplanin as a marker for mesothelioma. Pathol Int 2005;55:83-86.

41 Ordóñez NG. D2-40 and podoplanin are highly specific and sensitive immunohistochemical markers of 
epithelioid malignant mesothelioma. Hum Pathol 2005; 36:372-380.

42 Sienko A, Zander DS, Killen D, et al. D2-40 is a novel new marker of malignant mesothelioma (MM): tissue microarray study of 45 MM vs 409 lung carcinomas and primary non-mesothelial neoplasms of the pleura and chest wall. Mod Pathol 2005; 18(Suppl. 1):318A.

43 Kahn HJ, Bailey D, Marks A. Monoclonal antibody D240, a new marker of lymphatic endothelium, reacts with Kaposi's sarcoma and a subset of angiosarcomas. Mod Pathol 2002;15:434-440.

44 Breiteneder-Geleff S, Soleiman A, Kowalski H, et al. Angiosarcomas express mixed endothelial phenotypes of blood and lymphatic capillaries: podoplanin as a specific marker for lymphatic endothelium. Am J Pathol 1999;154:385-394.

45 Ordóñez NG. The diagnostic utility of immunohistochemistry and electron microscopy in distinguishing between peritoneal mesotheliomas and serous carcinomas: a comparative study. Mod Pathol (in press).

46 Ordóñez NG. The diagnostic utility of immunohistochemistry in distinguishing between epithelioid mesotheliomas and squamous carcinomas of the lung: A comparative study. Mod Pathol (in press).

47 Yilmazbayhan D, Esberk L, Dilege S, et al. Pulmonary large cell carcinoma with rhabdoid phenotype. Ann Diagn Pathol 2005;9:223-226.

48 Ordóñez NG. The immunohistochemical diagnosis of mesothelioma: a comparative study of epithelioid mesothelioma and lung adenocarcinoma. Am J Surg Pathol 2003;27:1031-1051.

49 Ordóñez NG. Thyroid transcription factor-1 is a marker of lung and thyroid carcinomas. Adv Anat Pathol 2000;7:123-127.

50 Guillou L, Wadden C, Coindre J-M, et al. 'Proximaltype' epithelioid sarcoma, a distinctive aggressive neoplasm showing rhabdoid features: clinicopathologic, immunohistochemical, and ultrastructural study of a series. Am J Surg Pathol 1997;21:130-146.

51 Hasegawa T, Matsuno Y, Shimoda T, et al. Proximaltype epithelioid sarcoma: a clinicopathologic study of 20 cases. Mod Pathol 2001;14:655-663.

52 Laskin WB, Miettinen M. Epithelioid sarcoma: new insights based on an extended immunohistochemical analysis. Arch Pathol Lab Med 2003;127: 1161-1168.

53 Arber DA, Kandalaft PL, Mehta P, et al. Vimentinnegative epithelioid sarcoma. The value of an immunohistochemical panel that includes CD34. Am J Surg Pathol 1993;17:302-307.

54 Miettinen M, Fanburg-Smith JC, Virolainen M, et al. Epithelioid sarcomas: an immunohistochemical analysis of 112 classical and variant cases and a discussion of the differential diagnosis. Hum Pathol 1999; 30:934-942.

55 Attanoos RL, Suvarna SK, Rhead E, et al. Malignant vascular tumours of the pleura in 'asbestos' workers and endothelial differentiation in malignant mesothelioma. Thorax 2000;55:860-863.

56 Lin BT-Y, Colby T, Gown AM, et al. Malignant vascular tumors of the serous membranes mimicking mesothelioma: a report of 14 cases. Am J Surg Pathol 1996;20:1431-1439.

57 Machen SK, Easley KA, Goldblum JR. Synovial sarcoma of the extremities: a clinicopathologic study of 34 cases, including semi-quantitative analysis of spindled, epithelial, and poorly differentiated areas. Am J Surg Pathol 1999;23:268-275.

58 Ordóñez NG, Mahfouz SM, Mackay B. Synovial sarcoma: an immunohistochemical and ultrastructural study. Hum Pathol 1990;21:733-749.

59 Miettinen M, Limon J, Niezabitowski A, et al. Calretinin and other mesothelioma markers in synovial sarcoma: analysis of antigenic similarities and differences with malignant mesothelioma. Am J Surg Pathol 2001;25:610-617.

60 Attanoos RL, Griffin A, Gibbs AR. The use of immunohistochemistry in distinguishing reactive from neoplastic mesothelium. A novel use for desmin and comparative evaluation with epithelial membrane antigen, p53 platelet-derived growth factor-receptor, P-glycoprotein and Bcl-2. Histopathology 2003;43: 231-238.

61 Cappello F, Barnes L. Synovial sarcoma and malignant mesothelioma of the pleura: review, differential diagnosis and possible role of apoptosis. Pathology 2001;33:142-148.

62 Chilosi M, Facchetti F, Tos APD, et al. bcl-2 expression in pleural and extrapleural solitary fibrous tumours. J Pathol 1997;181:362-367.

63 Suster S, Fisher C, Moran CA. Expression of bcl-2 oncoprotein in benign and malignant spindle cell tumors of soft tissue, skin, serosal surfaces, and gastrointestinal tract. Am J Surg Pathol 1998;22: 863-872.

64 Limon J, Mrozek K, Mandahl N, et al. Cytogenetics of synovial sarcoma. Presentation of 10 new cases and review of the literature. Genes Chromosomes Cancer 1991;3:338-345.

65 Smith S, Reeves BR, Wong L, et al. A consistent chromosome translocation in synovial sarcoma. Cancer Genet Cytogenet 1987;26:179-180.

66 Cessna $\mathrm{MH}$, Zhou $\mathrm{H}$, Perkins SL, et al. Are myogenin and MyoD1 expression specific for rhabdomyosarcoma? A study of 150 cases with emphasis on spindle cell mimics. Am J Surg Pathol 2001;25: 1150-1157.

67 Kumar S, Perlman E, Harris CA, et al. Myogenin is a specific marker for rhabdomyosarcoma: an immunohistochemical study in paraffin-embedded tissues. Mod Pathol 2000;13:988-993.

68 Afify AM, Al-Khafaji BM, Paulino AF, et al. Diagnostic use of muscle markers in the cytologic evaluation of serous fluids. Appl Immunohistochem Mol Morphol 2002;10:178-182.

69 Garcia-Prats MD, Ballestin C, Sotelo T, et al. A comparative evaluation of immunohistochemical markers for the differential diagnosis of malignant pleural tumours. Histopathology 1998;32:462-472.

70 González-Lois C, Ballentín C, Sotelo MT, et al. Combined use of novel epithelial (MOC-31) and mesothelial (HBME-1) immunohistochemical markers for optimal first line diagnostic distinction between mesothelioma and metastatic carcinoma in pleura. Histopathology 2001;38:528-534.

71 Hurlimann J. Desmin and neural marker expression in mesothelial cells and mesotheliomas. Hum Pathol 1994;25:753-757.

72 Truong LD, Rangdaeng S, Cagle P, et al. The diagnostic utility of desmin: a study of 584 cases and review of the literature. Am J Clin Pathol 1990;93: 305-314. 
73 Davidson B, Nielsen S, Christensen J, et al. The role of desmin and $\mathrm{N}$-cadherin in effusion cytology: a comparative study using established markers of mesothelial and epithelial cells. Am J Surg Pathol 2001; 25:1405-1412.

74 Kung ITM, Thallas V, Spencer EJ, et al. Expression of muscle actins in diffuse mesotheliomas. Hum Pathol 1995;26:565-570.
75 Mayall FG, Goddard H, Gibbs AR. Intermediate filament expression in mesotheliomas: leiomyoid mesotheliomas are not uncommon. Histopathology 1992;21:453-457.

76 Trupiano JK, Geisinger KR, Willingham MC, et al. Diffuse malignant mesothelioma of the peritoneum and pleura, analysis of markers. Mod Pathol 2004; $17: 476-481$ 